\title{
Mechanical Fruit Thinning Influences Fruit Quality, Yield, Return Fruit Set, and Cold Injury of Pecan
}

\author{
Michael W. Smith ${ }^{1}$, William Reid ${ }^{2}$, Becky Carroll, and Becky Cheary ${ }^{3}$ \\ Department of Horticulture and Landscape Architecture, Oklahoma State \\ University, Stillwater, OK 74078
}

Additional index words. Carya illinoinensis, nut thinning, kernel grading, nut size, cold damage, kernel percentage, crop load

\begin{abstract}
Pecan [Carya illinoinensis (Wangenh.) C. Koch] fruit were thinned from 'Mohawk' trees in Oklahoma and 'Giles' trees in Kansas with a mechanical trunk shaker. All trees bore an excessive crop load before shaking. Fruit thinning improved the kernel percentage, individual nut weight, and kernel grade of 'Mohawk', but nut characteristics of 'Giles' were not affected by fruit thinning. Cold injury, caused by a sudden temperature drop in November, was positively related to the percentage of fruiting shoots in both cultivars. Fruit set in 1992 was negatively related to the percentage of fruiting shoots in 1991 in both cultivars. Consistent annual fruit set could be induced in 'Giles' by fruit thinning, but return fruit set in 'Mohawk', even at high levels of thinning, was low. Fruit thinning reduced yield the year of thinning in both cultivars. Thus, 'Mohawk' trees should be thinned so that $50 \%$ to $60 \%$ of shoots bearing fruit at mid-canopy height would remain, and 'Giles' trees should be thinned similarly to $65 \%$ to $70 \%$.
\end{abstract}

Erratic production is a major problem affecting the pecan industry. Pecans tend to alternate years of high production with one or more years of low production (Sparks, 1986). During high-production years, individual nut weight, kernel percentage, and kernel grade are diminished compared to low-production years. Crane et al. (1934) reported that kernel development was positively related to the number of leaves per fruit and estimated that eight to 10 leaves per fruit were required for optimum kernel quality. Additionally, tree susceptibility to subsequent cold damage is increased when the crop load is high (Reid et al., 1993; Smith and Cotten, 1985; Wood, 1986).

Lack of return bloom has been associated with early defoliation (Hinrichs, 1962; Worley, 1979) and with the inhibitory effect of developing fruit on return bloom (Malstrom and McMeans, 1982; Reid et al., 1993; Smith et al., 1986). Management practices that maintain healthy foliage until fall frosts will not ensure adequate return bloom or fruit quality. Therefore, fruit thinning is essential to improve fruit quality and return bloom.

Several scientists have tested various chemicals for selectively thinning pecan fruit (Amling and Dozier, 1965; Dodge, 1944; Hinrichs et al., 1971; Sharpe, 1955; Smith and

\footnotetext{
Received for publication 10 Aug. 1992. Accepted for publication 15 Aug. 1993. Oklahoma Agricultural Experiment Station journal series no. J6275, and Kansas Agricultural Experiment Station journal series no. 93-72-J. The cost of publishing this paper was defrayed in part by the payment of page charges. Under postal regulations, this paper therefore must be hereby marked advertisement solely to indicate this fact.

${ }^{1}$ Professor.

${ }^{2}$ Research Horticulturist, Pecan Experiment Field, Kansas State Univ., Chetopa, KS 67336. ${ }^{3}$ Research Technician.
}

Harris, 1957; Wood, 1983, 1985). Although results from some of these studies have been promising, none of the chemicals is registered for pecans.

Mechanical fruit thinning appears to be a practical approach to overproduction, which results in poor quality and erratic yields. Sparks and Brack (1972) showed that removing fruit by hand, when the kernel was one-fourth to one-third developed, increased distillate flower production and fruit set the following year compared to shoots with fruit retained. Smith and Gallott (1990) demonstrated that thinning fruit with a trunk shaker equipped with doughnut pads, while fruit were in the liquid endosperm stage, increased nut weight, kernel percentage, and kernel grade compared to nonthinned trees. They also found return bloom was increased on 'Shoshoni', but not on 'Mohawk', by fruit thinning. Later work showed that fruit must be thinned before kernel deposition (the change from a liquid endosperm to a solid kernel) to ensure maximum return bloom (Reid et al., 1993). The recommended fruit thinning time is when the ovule is at least one-half expanded and in the liquid endospenn stage.

The work described above and frequent cold injury to pecan trees in Oklahoma and Kansas have demonstrated clearly the need to thin pecan fruit when the crop is excessive. While the optimum thinning time based on fruit development has been determined, the optimum crop load to achieve high-quality fruit with adequate return bloom has not been established. Therefore, this study was initiated to determine the effect of crop load after mechanical thinning on fruit quality, yield, and return bloom. Low temperatures during 2 and 3 Nov. 1991 injured trees, and the relationship between crop load and cold injury was determined. Additionally, we determined the distri- bution of fruit on the tree before and after thinning with a mechanical shaker.

Oklahoma-Spatial distribution of fruiting shoots. Six 'Mohawk' trees were selected to determine the spatial distribution of fruit before and after thinning. These trees were similar in size to and under the same management as those in the description of the Oklahoma study that follows. The percentage of fruiting shoots at the canopy periphery first was determined in a $1 \times 2-\mathrm{m}$ area at two locations in the top, middle, and bottom thirds of the tree. Fruit then were thinnedon 31 July 1991 using a mechanical trunk shaker equipped with doughnut pads (NutHustler model 2138; NutHustler-Savage Equipment Co., Madill, Okla.). The percentage of fruiting shoots was determined after thinning at the same locations, and the number of fruit per cluster was counted. Means and SE were calculated for the three heights in the tree.

Oklahoma-Fruit thinning of 'Mohawk'. Twenty-seven 'Mohawk' trees of uniform size $\left(0.068 \pm 0.003 \mathrm{~m}^{2}\right.$ cross-sectional trunk area at $60 \mathrm{~cm}$ above the ground) were selected for the study at the Pecan Research Station near Sparks, Okla. The trees were 20 years old, and $70 \%$ to $90 \%$ of their shoots bore fruit. The trees were spaced initially at $10.7 \times 10.7 \mathrm{~m}$ (88 trees/ha). During Winter 1989-90, half of the trees were removed (44 trees/ha). Pest control and fertility practices were those recommended for commercial pecan management (Taylor et al., 1992; von Broembsen et al., 1992). The trees were not irrigated.

Fruit were thinned on31 July 1991 using the trunk shaker described previously. At the time of thinning, the ovule was $\approx 50 \%$ expanded and in the liquid endosperm stage. Trees were thinned to give a wide range in the percentage of shoots that retained fruit clusters (8\% to $90 \%$ of the shoots bearing fruit). The percentage of shoots bearing fruit was determined at the canopy periphery in a $1 \times 2-m$ area at mid-canopy height on two sides of each tree. We counted all shoots, regardless of length, and recorded the number of fruit per shoot.

At harvest, triplicate 20-nut samples per tree were collected before and after being processed through a pecan cleaner (NutHustlerSavage Equipment Co.) to remove light nuts and debris. Nut diameter and length were measured, samples were weighed and cracked, and the kernel percentage was determined. Kernels (40 halves per sample, three samples per tree) were graded from uncleaned and cleaned samples using industry grading standards (Winter, 1979). The kernel grades were 1 = brightly colored, full bodied, and solid; 2 = brightly colored and lightweight; 3 = amber and light weight, with adhering material; and 4 = poorly developed and shriveled (would be discarded). The kernel rating system did not consider insect damage.

On 2 and 3 Nov. 1991, temperatures dropped to $-12 \mathrm{C}$. There had been no prior freezing temperatures, and trees were fully foliated. This sudden temperature decrease, coupled with no preceding cold-acclimating temperatures, injured some trees. During June 1992, trees were rated for cold injury using the 
Table 1. Percentage of fruiting shoots in the top, middle, and bottom thirds of 'Mohawk' pecan trees before and after mechanical fruit thinning with a trunk shaker, and the number of fruit per cluster after mechanical fruit thinning.

\begin{tabular}{lccc}
\hline & \multicolumn{2}{c}{ Fruiting shoots (\%) } & - \\
\cline { 2 - 4 } $\begin{array}{l}\text { Location } \\
\text { in tree }\end{array}$ & $\begin{array}{c}\text { Before } \\
\text { thinning }\end{array}$ & $\begin{array}{c}\text { After } \\
\text { thinning }\end{array}$ & $\begin{array}{c}\text { Fruit } \\
\text { per cluster }\end{array}$ \\
\hline Top & $40.0 \pm 10.5^{y}$ & $32.7 \pm 6.0$ & $2.5 \pm 0.2$ \\
Middle & $68.8 \pm 1.7$ & $41.2 \pm 2.3$ & $2.6 \pm 0.1$ \\
Bottom & $72.3 \pm 3.1$ & $50.2 \pm 4.1$ & $2.6 \pm 0.1$ \\
\hline
\end{tabular}

${ }^{2}$ The number of fruit per cluster after trees were thinned.

'Mean of six replications $\pm S E$.

following scale: 1 = no injury; 2 = death of 1 and 2-year-old shoots; $3=$ death of branches $\geq 3$ years old, but survival of scaffold limbs; 4 $=$ death of at least one scaffold limb; and $5=$ death of the tree.

Fruit set the year following thinning (1992) was measured 10 June. Vegetative and fruiting shoots at mid-canopy height were counted in a $1 \times 2-m$ area at two locations, and the percentage of fruiting shoots was calculated.

Data were fitted to selected linear and nonlinear models, with the best model chosen based on the smallest standard error of the regression, the sequential analysis of variance of the equation components, and the analysis of variance of the model (Draper and Smith, 1966). Confidence limits (90\%) were calculated for the model.

Kansas-Fruit thinning of 'Giles', For this study at the Pecan Experiment Field in Chetopa Kan., we selected 20 'Giles' trees with a 0.069 $\pm 0.012 \mathrm{~m}^{2}$ cross-sectional trunk area at $60 \mathrm{~cm}$ above the ground. Trees were 28 years old, with $80 \%$ to $95 \%$ of their shoots bearing fruit. Trees were spaced $10.6 \times 21.3 \mathrm{~m}$ (44 trees/ha). Pest control and fertility practices were those recommended for a commercial orchard (Reid, 1992; von Broembsen et al., 1992). Trees were not irrigated.

Fruit were thinned on 1 Aug. 1991 with the same shaker used in the Oklahoma study. At the time of thinning, the ovule was $\approx 75 \%$ expanded and in the liquid endosperm stage. The percentage of fruit-bearing shoots after thinning (62\% to $97 \%$ ) was determined in a 1 $\times 2-\mathrm{m}$ area at mid-canopy height. Methods of nut sample collection and analysis, and measurement of return fruit set (1992) were identical to those for the Oklahoma study.

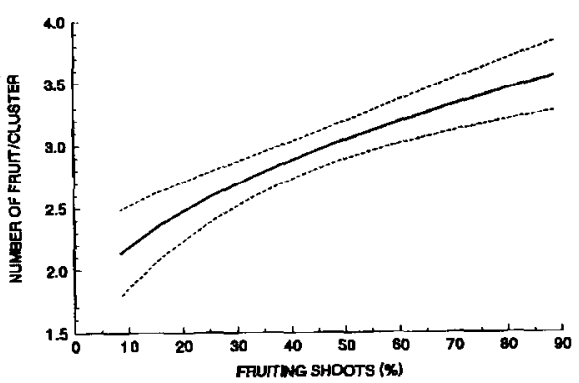

Fig. 1. The relationship between the percentage of fruiting shoots per tree and the number of fruit per cluster on shoots that bore fruit after thinning 'Mohawk' pecan with a trunk shaker $(\mathrm{y}=1.4956$ $+0.2190 \mathrm{x}, r^{2}=0.434, P \geq 0.001$ ). Dashed lines indicate the $90 \%$ confidence limits.
Temperatures at the Kansas site dropped to $-8 \mathrm{C}$ on 2 and 3 Nov. 1991. There had been no prior freezing temperatures, and the trees were fully foliated. Four l-year-old shoot samples were collected during Dec. 1991, and the cambium area was rated for cold damage. The rating scale was $1=$ no injury, $2=$ slightly discolored spots in the cambium area, $3=$ brown streaking in the cambium region (previous experience indicates that shoot death would not be expected, but growth might be reduced), $4=$ major browning in the cambium region (greatly diminished growth, and some shoot death would be expected), and $5=$ dead shoot.

Oklahoma-Spatial distribution of fruiting shoots. Fruiting was greatest on the trees' lower shoots and declined as height increased (Table 1), indicating that trees were adequately spaced and vigorous. Mechanical thinning reduced the percentage of fruiting clusters at all locations in the tree. Fruiting shoots were reduced by $18 \%, 40 \%$, and $30 \%$ in the upper, middle, and lower thirds of the canopy, respectively. The percentage of fruiting shoots remaining after thinning ranged from onethird in the upper third of the canopy to half in the lower third of the canopy, with an average fruit cluster size of 2.6 over the entire tree.

Oklahoma-Fruit thinning of 'Mohawk'. The number of fruit per cluster was related positively to the percentage of fruiting shoots per tree after the trees were thinned (Fig. 1), indicating thinning occurred within the cluster. We observed that most 'Mohawk' fruit were dislodged as individual fruit, and only $\approx 1 \%$ of the fruit were dislodged as entire clusters. Thus, mechanical thinning of 'Mohawk' apparently reduced the percentage

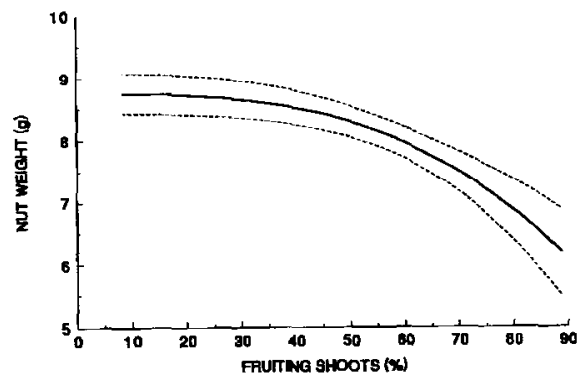

Fig. 2. The relationship between the percentage of fruiting shoots per tree after fruit thinning 'Mohawk' pecan and the individual nut weight of uncleaned samples $\left(y=8.754-3.67 \times 10^{6} x^{3}\right.$, $\left.r^{2}=0.499, P \geq 0.001\right)$. Dashed lines indicate the $90 \%$ confidence limits. of fruiting shoots by removing most fruit singly, until the entire cluster was removed. In contrast, our experience with 'Western' and 'Maramec' indicates that $\approx 10 \%$ of the fruit were dislodged as clusters, and the force required to dislodge the fruit was greater than that required for 'Mohawk' (data not shown). However, the force required to dislodge the fruit was not related closely to fruit size. For example, dislodging the fruit from 'Peruque' and 'Giles' (small-fruited cultivars) required about the same shaking force as the largefruited 'Mohawk'. 'Peruque' and 'Giles' reacted to shaking like 'Mohawk' in that fruit were dislodged singly rather than in clusters.

Individual nut weight from the uncleaned samples was related negatively to the percentage of fruiting shoots after the trees were timed (Fig. 2). The relationship between individual nut weight and the percentage of fruiting shoots was curvilinear, with a rapid decrease in nut weight when the proportion of fruiting shoots was $>50 \%$ to $60 \%$. Individual nut weight from cleaned samples was curvilinearly related to the percentage of fruiting shoots $\left(r^{2}=0.517, P \geq 0.001\right)$ (data not shown). The shape of the curve was similar to that for uncleaned samples, although the $y$ intercept was higher, because many lightweight nuts were removed during cleaning.

Nut length and width were not related to the percentage of fruiting shoots (data not shown). Fruit size increased gradually at first, then rapidly, until ovary wall Signification (Diver et al., 1984). When the shell hardened, the fruit ceased lengthening and widening. Fruit thinned on 31 July were nearly full size, and ovary wall signification was completed soon after fruit thinning. It is unlikely that fruit thinning during this period affected fruit size.

The kernel percentage from uncleaned samples was related negatively to the percentage of fruiting shoots after thinning (Fig. 3). The relationship of kernel percentage to the percentage of fruiting shoots was curvilinear, with a rapid decline in kernel percentage when the percentage of fruiting shoots per tree was $>50 \%$ to $60 \%$. Kernel percentage of cleaned samples was curvilinearly related to the percentage of fruiting shoots, and the shape of the curve was similar to that for uncleaned samples (data not shown).

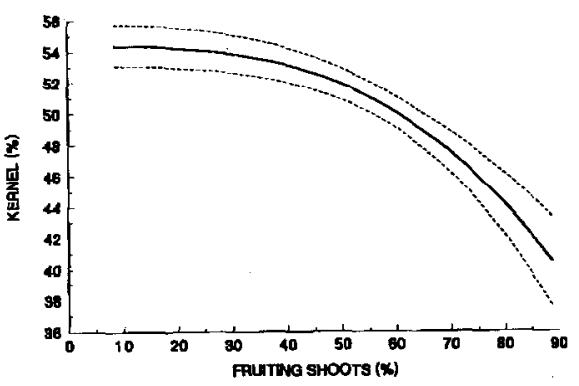

Fig. 3. The relationship between the percentage of fruiting shoots per tree after fruit thinning 'Mohawk' pecan and the kernel percentage of uncleaned samples $\left(y=54.391-1.99 \times 10^{-5} x^{3}\right.$, $r^{2}=0.639, P \geq 0.001$ ). Dashed lines indicate the $90 \%$ confidence limits. 

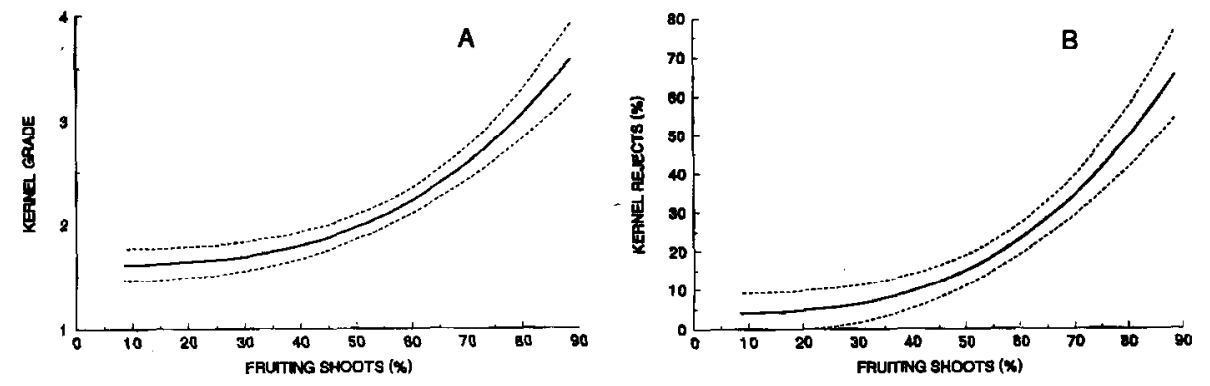

Fig. 4. The relationship between the percentage of fruiting shoots per tree after fruit thinning 'Mohawk' pecan and $(\mathbf{A})$ the average kernel grade of uncleaned samples $\left(\mathrm{y}=1.611+2.824 \times 10^{-6} \mathrm{x}^{3}, r^{2}=0.727, P\right.$ $\geq 0.001$ ), and (B) the percentage of kernel rejects (grade 4) in uncleaned samples $(y=3.902+8.838 \times$ $\left.10^{-5} \mathrm{x}^{3}, r^{2}=0.694, P \geq 0.001\right)$. Dashed lines indicate the $90 \%$ confidence limits.

The numerical grade of kernels and the percentage from uncleaned samples that would be rejected by shellers (grade 4) were related positively to the percentage of fruiting shoots after thinning (Fig. $4 \mathrm{~A}$ and $\mathrm{B}$ ). A rapid decrease in kernel quality and increase in kernel rejects occurred when the percentage of fruiting shoots was $>50 \%$ to $60 \%$. These data indicate that when the percentage of fruiting shoots on 'Mohawk' is $>50 \%$ to $60 \%$ of the nut weight, kernel percentage and nut quality decline rapidly.

Yield was related positively to the percentage of fruiting shoots after thinning (Fig. 5). Thus, yield was reduced by fruit thinning, as expected. However, because kernel percentage and kernel grade were substantially reduced when $>50 \%$ to $60 \%$ of the shoots were fruiting, there is little economic justification in greater yields at the expense of kernel yield and kernel quality. In fact, yield levels when $50 \%$ to $60 \%$ of the shoots were fruiting would be of greater value than the highest yield level because of the differences in kernel quality.

Cold injury was related curvilinearly to the percentage of fruiting shoots after thinning (Fig. 6). The amount of cold injury increased slowly as the percentage of fruiting shoots increased from $8 \%$ to $40 \%$, then rapidly when the percentage of fruiting shoots was $>40 \%$. In Oklahoma, damaging low temperatures during the fall or winter occur $\approx 1$ in 9 years. This frequency indicates that cold injury can be a major problem on cultivars that tend to overbear and are susceptible to cold injury. Controlling the crop load by mechanical thinning

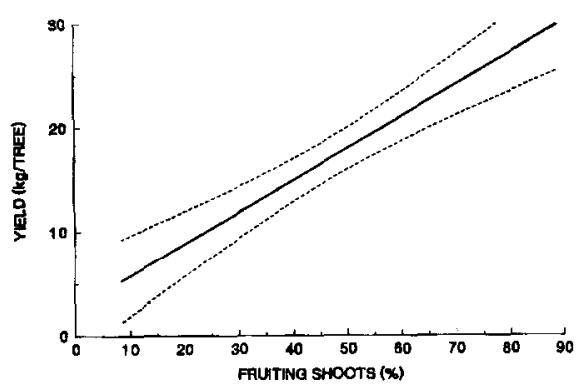

Fig. 5. The relationship between the percentage of fruiting shoots per tree after thinning 'Mohawk' pecan and individual tree yield $(y=2.659+$ $\left.0.307 \mathrm{x}, r^{2}=0.619, P \geq 0.001\right)$. Dashed lines indicate the $90 \%$ confidence limits. can reduce the severity of cold injury, and in extreme cases can prevent tree death.

Fruit set in 1992, expressed as percent fruiting shoots, was related to the percentage of fruiting shoots in 1991 and the severity of cold injury from Fall 1991 (Fig. 7). Cold injury had the greatest impact on return fruit set (partial $r^{2}=0.471$ ), and the percentage of fruiting shoots during 1991 accounted for an additional $7 \%$ of the data's variation (model $R^{2}=0.543$ ). A cold-injury rating of 2 (death of some 1- and 2-year-old shoots) resulted in a greatly diminished fruit set compared to uninjured trees (rating $=1$ ); trees with an injury rating $\geq 3$ had no fruit set the following year. Return fruit set of uninjured 'Mohawk' trees was low. Similarly, Smith and Gallott (1990) reported fruit thinning had little impact on return flowering of 'Mohawk'; however, return flowering of 'Shoshoni' was improved greatly. 'Mohawk' may be more sensitive than other cultivars to the inhibitory effects of developing fruit on induction of distillate flowers. Alternatively, low temperatures during the fall may have damaged buds and wood, preventing distillate flower development without any apparent shoot death.

Kansas-Fruit thinning of 'Giles'. The number of fruit per cluster after mechanical thinning was related positively to the percent-

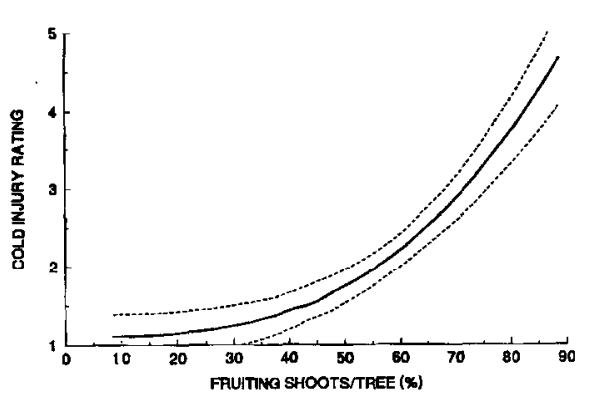

Fig. 6. The relationship between the percentage of fruiting shoots per tree after thinning 'Mohawk' pecan on 31 July 1991 and the tree cold injury that occurred on 2 and 3 Nov. 1991. Cold injury was rated during June $1992(\mathrm{y}=1.097+5.128$ $\left.\times 10^{-6} \mathrm{x}^{3}, r^{2}=0.721, P \geq 0.001\right)$. Dashed lines indicate the $90 \%$ confidence limits. The rating system was $1=$ no injury; $2=$ death of many $1-$ and 2-year-old shoots; $3=$ death of $\geq 3$-year-old branches, but no scaffold death; $4=$ death of at least one scaffold limb; and $5=$ tree death age of fruiting shoots (Fig. 8). Removing 'Giles' fruit by mechanical thinning was similar to that for 'Mohawk' in that fruit were removed singly from the cluster rather than as entire clusters.

Thinning 'Giles' fruit did not affect the kernel percentage $(49.7 \% \pm 1.5 \%)$, individual nut weight $(4.5 \pm 0.5 \mathrm{~g} / \mathrm{nut})$, or kernel grade $(1.6 \pm 0.3)$ of cleaned or uncleaned nut samples (data not shown). The percentage of fruiting shoots after thinning was related positively to yield (Fig. 9), indicating that thinning fruit reduced yield.

There was a strong negative relationship between the percentage of shoots bearing fruit in 1991 and in 1992 (Fig. 10), indicating that fruit thinning could be used to induce uniform annual production in 'Glles'. These data suggest that uniform annual crops could be achieved if trees were thinned so that $\approx 65 \%$ to $70 \%$ of shoots bearing fruit at mid-canopy height would remain.

The percentage of fruiting shoots of 'Giles' in 1991 was related positively to the coldinjury rating (Fig. 11). However, the percentage of shoots bearing fruit in 1992 was not related to the cold-injury rating (data not shown). Cold injury of 'Giles' was less severe than that of 'Mohawk' for two reasons. First, temperatures at the Oklahoma site were lower than at the Kansas site, and second, 'Giles' is a northern-type cultivar that is more coldhardy than 'Mohawk'.

Our results indicated that fruit thinning was greatest in the middle of the tree, and least at the top of the tree. This thinning pattern is desirable, because the upper canopy has the greatest light exposure and likely would be capable of supporting more fruit than lower, shaded portions. However, this pattern of thinning may be affected by the tree's structure (i.e., trees with a pendulous growth habit, such as 'San Saba Improved' or 'Cheyenne', may thin differently than an upright tree such as 'Mohawk') or size, or the type and size of the trunk shaker used.

Mechanically thinning pecan fruit has sev-

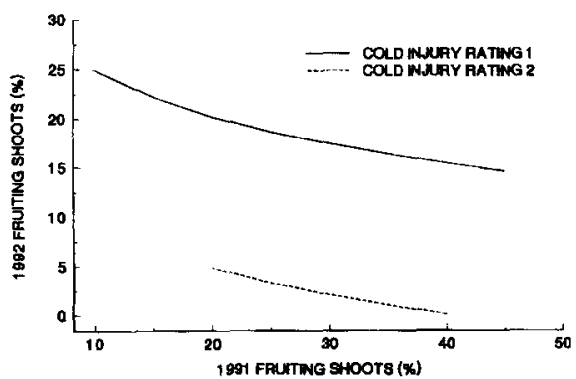

Fig. 7. The relationship between the percentage of fruiting shoots per tree after thinning 'Mohawk' pecan in 1991 and the tree cold-injury rating with the percentage of fruiting shoots in 1992 [y $=-36.55-15.77 \times \log$ (percent fruiting shoots) $+77.304 \times 1 /$ (cold-injury rating) $+77.467 \times$ $\log _{10}$ (cold-injury rating), $\left.R^{2}=0.543, P \geq 0.001\right]$. The cold-injury rating system was $1=$ no injury; 2 = death of many 1 - and 2-year-old shoots; $3=$ death of $\geq 3$-year-old branches, but no scaffold death; $4=$ death of at least one scaffold limb; and $5=$ tree death. 


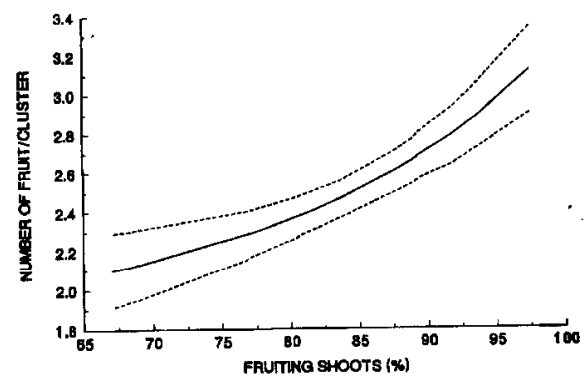

Fig. 8. The relationship between the percentage of fruiting shoots per tree and the number of fruit per cluster on shoots that bore fruit after thinning 'Giles' with a trunk shaker [y $=1 /(0.549+$ $\left.\left.2.472 \mathrm{x}^{3}\right), r^{2}=0.588, P \geq 0.001\right]$. Dashed lines indicate the $90 \%$ confidence limits.

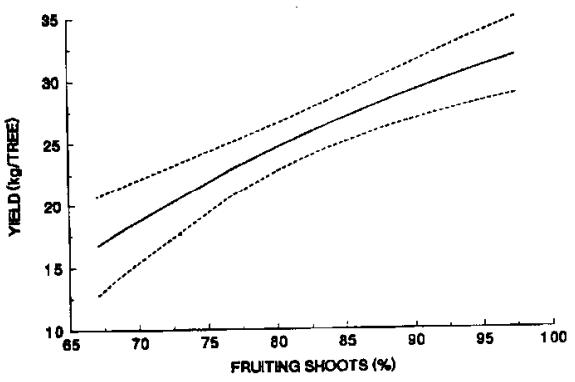

Fig. 9. The relationship between the percentage of fruiting shoots per tree after thinning 'Giles' pecan and individual tree yield $(\mathrm{y}=65.358$ $3261.18 / \mathrm{x}, r^{2}=0.591, P \geq 0.001$ ). Dashed lines indicate the $90 \%$ confidence limits.

eral benefits when the ovule is $50 \%$ to $100 \%$ expanded in the liquid endosperm stage. In 'Mohawk', kernel percentage, individual nut weight, and kernel grade were increased. However, in 'Giles', these nut characteristics were not affected. This may relate closely to the nut size and the fruit count per cluster. In 'Mohawk', the average nut weight was $8.1 \mathrm{~g}$, with 3.7 fruit per cluster (unthinned); in 'Giles', nut weight averaged $4.5 \mathrm{~g}$, with 3.1 fruit per cluster. An individual fruiting shoot of 'Giles' would support $14 \mathrm{~g}$ of nuts, while 'Mohawk' would support $30 \mathrm{~g}$ of nuts (excluding the involucre), $114 \%$ more nut mass per shoot than 'Giles'. This difference indicates that 'Mohawk' requires a higher leaf : fruit ratio than 'Giles', and the fruit quality of 'Mohawk' is more likely to be affected by crop load than 'Giles'.

Fruit thinning had a greater impact on return fruit set in 'Giles' than in 'Mohawk'. In 'Giles', adequate return fruit set could be induced by thinning the trees so that $65 \%$ to $70 \%$ of shoots bearing fruit at mid-canopy height would remain. However, in 'Mohawk', thinning fruit to $\leq 50 \%$ of the shoots bearing fruit resulted in $\leq 25 \%$ of those shoots setting fruit the following year. Although visual estimates of cold injury were accounted for in the model, damage to the buds or shoots, which was not apparent, may have accounted for the low return fruit set. However, earlier work on 'Mohawk' yielded similar results (Smith and Gallott, 1990). Differences in the return fruit

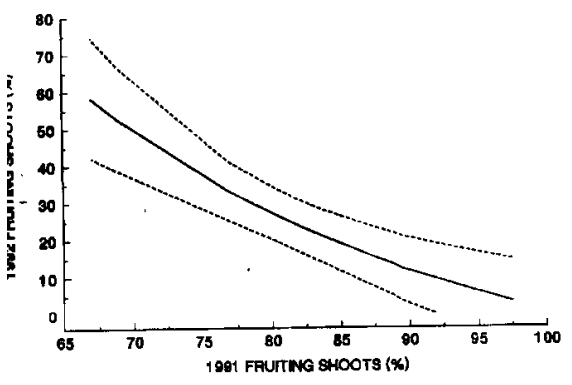

Fig. 10. The relationship between the percentage of fruiting shoots per tree after thinning 'Giles' pecan in 1991 and the percentage of fruiting shoots in $1992\left(\mathrm{y}=-46.156+469576 / \mathrm{x}^{2}, r^{2}=\right.$ $0.511, P \geq 0.001$ ). Dashed lines indicate the $90 \%$ confidence limits.

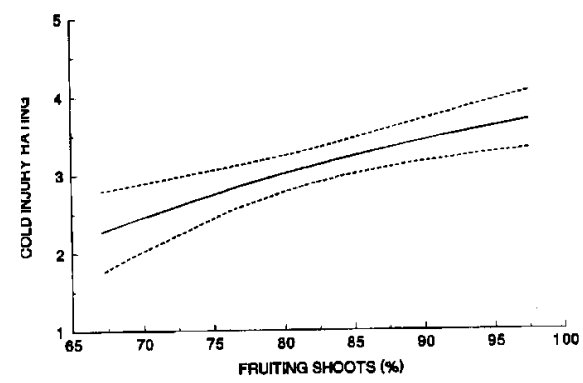

Fig. 11. The relationship between the percentage of fruiting shoots per tree after thinning 'Giles' pecan on 1 Aug. 1991 and the cold injury that occurred on 2 and 3 Nov. 1991. Cold injury was rated during Dec. $1991\left(\mathrm{y}=6.83-305.7 / \mathrm{x}, r^{2}=\right.$ $0.362, P \geq 0.01$ ). Dashed lines indicated the $90 \%$ confidence limits. The rating system was $1=$ no injury, 2 = slight discoloration in the cambium region, $3=$ discolored streaking in the cambium region, $4=$ major discolored areas of the cambium region, and $5=$ dead.

set of 'Giles' and 'Mohawk' maybe attributed to the greater carbohydrate demand in 'Mohawk' to develop large fruit, the slightly earlier ripening of 'Giles' ( $\approx 10$ days), or a higher production of flowering inhibitors by 'Mohawk' fruit.

Based on these results and those of earlier work (Reid et al., 1993; Smith and Gallott, 1990), 'Mohawk' trees should be thinned so that $\approx 50 \%$ to $60 \%$ of shoots bearing fruit at mid-canopy height would remain, and 'Giles' trees should be thinned similarly to $\approx 65 \%$ to $70 \%$. Thinning should occur at $50 \%$ to $100 \%$ ovule expansion and during the liquid endosperm stage. These thinning guidelines should improve fruit quality of 'Mohawk' and increase return fruit set, and induce annual cropping in 'Giles'. Our experience indicates that pecan cultivars producing fruit similar in size to these two cultivars will respond in a similar manner. However, other large-fruited cultivars may yield higher return fruit sets than 'Mohawk' when thinned following these guidelines.

\section{Literature Cited}

Amling, H.J. and W.A. Dozier, Jr. 1965. Chemical thinning of the Stuart pecan. Proc. Southeastern Pecan Growers' Assn. 58:92.
Crane, H.L., M.B. Hardy, N.H. Loomis, and F.N Dodge. 1934. Effect of nut thinning on size, degree of filling, and annual yields of pecans. Proc. Amer. Soc. Hort. Sci. 45:59-62.

Diver, S.G., M.W. Smith, and R.W. McNew. 1984. Influence of fruit development on seasonal elemental concentrations and distribution in fruit and leaves of pecan. Commun. Soil Sci. \& Plant Anal. 15:619-637.

Dodge, F.N. 1944. Reducing the set of pecan nuts by spraying in flower with phytotoxicants. Proc. Amer. Soc. Hort. Sci. 45:59-62.

Draper, N.R. and H. Smith. 1966. Applied regression analysis. Wiley, New York.

Hinrichs, H.A. 1962. Pecan industry and some research developments in Oklahoma. Annu. Rpt. Northern Nut Growers' Assn. 53:80-85.

Hinrichs, H. A., D.W. Ramming, and D.A. Hopfer. 1971. Effects of ethephon on thinning nuts and loosening shucks of pecan. Annu. Rpt. Northern Nut Growers' Assn. 62:105-108.

Malstrom, H.L. and J.L. McMeans. 1982. Shoot length and previous fruiting affect subsequent growth and nut production of 'Moneymaker' pecan. HortScience 17:970-972.

Reid, W. 1992. Growing pecans in Kansas. Kansas Coop. Ext. Serv. Misc. Fact Sheet 1025.

Reid, W., S.M. Huslig, M.W. Smith, N. Maness, and J. Whitworth. 1993. Fruit-removal time influences return bloom in pecan. HortScience 28:800-802.

Sharpe, R.H. 1955. Tests on thinning of heavy pecan crops with growth regulators. Proc. Southeastern Pecan Growers' Assn. 48:62-68.

Smith, C.L. and O.W. Harris. 1957. Chemical thinning of pecan crops. Proc. Southeastern Pecan Growers' Assn. 50:60-63.

Smith, M.W. and B.C. Cotten. 1985. Relationship of leaf elemental concentrations and yield to cold damage of 'Western' pecan. HortScience 20:420-422.

Smith, M.W. and J.C. Gallott. 1990. Mechanical thinning of pecan fruit. HortScience 25:414416.

Smith, M.W., R.W. McNew, P.L. Ager, and B.C. Cotten. 1986. Seasonal changes in the carbohydrate concentration in pecan shoots and their relationship to flowering. J. Amer. Soc. Hort. Sci. 111:558-561.

Sparks, D. 1986. Pecan, p. 323-339. In: S.P. Monselise (ed.). Handbook of fruit set and development. CRC, Boca Raton, Fla.

Sparks, D. and C.E. Brack. 1972. Return bloom and fruit set of pecan from leaf and fruit removal. HortScience 7:131-132.

Taylor, G., G.V. Johnson, and M.W. Smith. 1992. Fertilizing pecan and fruit trees. Oklahoma State Univ. Ext. Facts 6232.

von Broembsen, S., S. Coppock, and G. Taylor. 1992. Pecan insect and disease control-1992. Oklahoma State Univ. Current Rpt. 6209.

Winter, N. 1979. Pecan grading guidelines, an aid to marketing. Pecan South 6(6):22-27.

Wood, B.W. 1983. Fruit thinning of pecan with ethephon. HortScience 18:53-54.

Wood, B.W. 1985. Effect of ethephon on IAA transport, IAA conjugation, and antidotal action of NAA in relation to leaf abscission of pecan. J. Amer. Soc. Hort. Sci. 110:340-343.

Wood, B.W. 1986. Cold injury susceptibility of pecan as influenced by cultivar, carbohydrates and crop load. HortScience 21:285-286.

Worley, R. 1979. Pecan yield, quality, nutlet set, and spring growth as a response to time of fall defoliation. J. Amer. Soc. Hort. Sci. 112:346351. 